\title{
Pengaruh Store Environment Terhadap Customer Evaluation Serta Dampaknya Pada Customer Response Di Toko Ritel
}

\author{
Halim, L.H.P. ${ }^{1}$, Barata, D.D. ${ }^{2}$ \\ ${ }^{1}$ Program Studi Manajemen, Universitas Pelita Harapan, pranatahalim@gmail.com \\ ${ }^{2}$ Program Studi Manajemen, Universitas Pembangunan Jaya, dion.dewa@upj.ac.id
}

\begin{abstract}
Retail industry in Indonesia has develop significantly for the past 5 years and will continue to grow in the future. Retail store will compete to offer unique shopping experience and exclusive product by using store-as-a-brand strategy in order to create good relationship with the customers. This research aims to analyze the effect of store environment in retail apparel store towards customer evaluation, as well as the impact on customer response in retail. Data used in this research is retail customers aged 18 - 35 years old with total number of 338 respondents. Data are analyzed with Structural Equation Modelling. The result shows that social, design, ambient, and merchandise cues have significant effect towards cognitive evaluations on the store and product, while cognitive evaluations on store and product, and also cognitive evaluations on store has significant effect towards affective evaluations on store and product, affective evaluations on store has significant effect towards approach - avoidance behavior, As for the comparison, the relationship between affective evaluations on products doesn't have significant effect towards affective evaluations.
\end{abstract}

Keywords : Retail, Store, Environment, Customer, Evaluation, Response

\begin{abstract}
Abstrak : Industri retail di Indonesia akan berkembang secara signifikan pada tahun 2013 - 2018. Toko retail akan bersaing untuk menawarkan pengalaman belanja yang unik dan produk eksklusif dengan menggunakan strategi toko sebagai merek dalam rangka menciptakan hubungan yang baik dengan pelanggan. Penelitian ini bertujuan untuk menganalisis pengaruh Store environment terhadap customer evaluation, serta dampaknya terhadap customer response di ritel. Data yang digunakan dalam penelitian ini adalah 338 pelanggan ritel berusia 18, berusia 35 tahun dan dianalisis dengan structural equation modelling. Hasil penelitian menunjukkan bahwa ocial, design, ambient, dan merchandise cues memiliki pengaruh yang signifikan terhadap evaluasi kognitif di toko dan produk, sementara evaluasi kognitif di toko dan produk, serta evaluasi kognitif di toko memiliki pengaruh yang signifikan terhadap evaluasi afektif di toko dan produk, evaluasi afektif di toko memiliki pengaruh yang signifikan terhadap approach avoidance behavior. Adapun perbandingan, hubungan antara evaluasi afektif pada produk tidak memiliki pengaruh yang signifikan terhadap evaluasi afektif.
\end{abstract}

Kata Kunci : Retail, Store, Environment, Customer, Evaluation, Response

\section{LATAR BELAKANG}

Industri retail apparel di Indonesia akan mengalami pertumbuhan yang signifikan sebesar 6\% dalam 5 tahun antara 2013 sampai 2018, diperkirakan nilai ini akan berkembang sampai dengan USD 7 miliar pada akhir 2018 ("Indonesian apparel", 2014). Berdasarkan penelitian, performa industri retail apparel juga diperkirakan melaju cepat dari 2014 sampai 2019 (“Apparel Retail”, 2015). Hal ini menjadi peluang untuk para pelaku industri retail apparel di Indonesia untuk meraup pasar yang lebih banyak dan membuat persaingan akan lebih ketat. Beberapa merek fashion seperti H\&M, Gap, Zara, 
dan Uniqlo akan menambah toko - toko di Asia agar dapat meraup pasar yang lebih besar lagi yang menarget golongan menengah dan atas (Cheng, 2014).

Pelanggan akan bersikap lebih selektif dalam pemilihan toko, juga didorong oleh keinginan mereka untuk mendapatkan pengalaman belanja dan produk yang unik (Kumar \& Kim, 2014). Menurut Floor, masing - masing toko harus menawarkan sesuatu yang spesial dan berbeda dari produk mereka agar dapat bersaing dengan lebih baik (dalam Kumar \& Kim, 2014).

Para pelaku retail memperkenalkan private brand yang mampu menjadikan produk mereka unik dan berbeda dibandingkan dengan para pelaku retail lainnya, dan langsung masuk dalam persaingan antar private brand dan merek - merek terkenal lainnya dalam kategori produk tersebut (Ailawadi \& Keller, 2004). Namun, karena persaingan private brand yang semakin ketat, keuntungan kompetitif yang didapatkan para pelaku retail juga semakin berkurang. Hal ini dapat diatasi dengan cara memberikan pengalaman belanja yang unik dan produk yang eksklusif.

Floor dalam Kumar \& Kim (2014) menyatakan bahwa hal ini dapat dicapai dengan menggunakan strategi storeas-abrand, yaitu strategi toko retail yang berubah dari distributor produk menjadi toko retail dengan private brand yang kuat agar dapat menciptakan hubungan rasional dan emosional dengan pelanggan. Dalam strategi store-as-abrand, para pelaku retail menggabungkan store atmosphere dan merchandise image untuk membentuk experience bagi pelanggan (Burt \& Davies, 2010).

Floor dalam Kumar \& Kim (2014), juga menyatakan bahwa strategi ini mengharuskan para pelaku retail untuk lebih fokus kepada faktor - faktor yang mempengaruhi indera pelanggan (store atmosphere) dan variasi produk di dalam toko. Menurut Baker et al., (1994), pelanggan akan melakukan interaksi dengan lingkungan toko retail selama proses belanja dan pada akhirnya akan mempengaruhi keputusan mereka. Kemudian, Kumar \& Kim (2014) menyimpulkan bahwa jika pelanggan merasa tidak ada kecocokan diantara variasi produk dan store atmosphere, maka akan mempengaruhi response dari pelanggan, yaitu pelanggan akan meninggalkan satu toko dan pindah ke toko lainnya.

Objek penelitian adalah salah satu toko ritel yang terletak di Jakarta, yaitu Grand Indonesia, Central Park, Senayan City, Kota Kasablanka, dan Pondok Indah Mall. Objek penelitian ini adalah toko retail apparel yang menyediakan apparel bagi pria. Tentunya beberapa perilaku belanja pria harus menjadi perhatian dalam penelitian ini. Menurut Azevodo et al., (2008), dalam proses belanja, pria lebih memilih toko yang memiliki store atmosphere yang menyenangkan dan juga memperhatikan merchandise cues.

Melihat perilaku belanja ini, dapat diartikan bahwa pria lebih memperhatikan kualitas dan variasi produk. Menurut Teije (2015), pria akan menilai pengalamannya terhadap toko tersebut lebih negatif jika ada karyawan toko yang kurang mengerti tentang produk dan tidak dapat memberi saran dalam memilih produk. Hal ini disebabkan karena pria cenderung mengalami kesulitan untuk mencari produk pilihan, terutama jika susunan produk di toko berantakan dan informasi yang tertulis di lokasi produk tidak jelas. Jadi, jika para pelaku retail ingin agar pria bisa tinggal lebih lama di toko, maka mereka harus memberikan pengalaman yang menyenangkan bagi pelanggan pria.

Lebih lanjut lagi, jika pelanggan pria bermasalah dengan toko, loyalitas pelanggan pria akan turun sejauh $40 \%$ (Teije, 2015). Dengan demikian, para pelaku retail apparel pria disarankan untuk lebih mengoptimalkan suasana toko.

Penelitian ini penting untuk mempelajari pengaruh dari kombinasi store atmosphere dan merchandise image 
untuk menghasilkan customer responses pada pelanggan toko retail apparel, sehingga diharapkan dapat menjadi masukan kepada toko retail apparel di Jakarta untuk menarik pelanggan lebih banyak lagi.

\section{LANDASAN TEORI \\ Retail Management}

Berman \& Evans (2007) menyatakan bahwa retailing adalah aktivitas bisnis kepada konsumen akhir yang mencakup penjualan barang dan jasa kepada konsumen untuk konsumsi pribadi, keluarga, atau kebutuhan rumah - tangga. Usaha retail mencakup penjualan produk fisik dan jasa, yang mana menjadi penyumbang ekonomi yang penting bagi suatu negara dan menjadi cerminan performa ekonomi suatu negara.

Menurut Berman \& Evans (2007), retail adalah tahap terakhir dari proses distribusi yang melibatkan semua pihak dalam proses perpindahan fisik dan kepemilikan dari sebuah barang atau jasa dari produsen ke konsumen. Retailer sering berperan sebagai penghubung antara produsen, pedagang grosir, dan konsumen; retailer membeli bermacam macam barang dari sumber yang berbeda dalam jumlah besar, dan menjual dalam jumlah kecil. Retailer juga bertugas untuk berkomunikasi dengan konsumen, pedagang grosir, dan produsen.

$$
\text { Berman \& Evans (2007), }
$$

menyatakan bahwa konsep retail mencakup: customer orientation - retailer menentukan kebutuhan konsumen kemudian berusaha memenuhi kebutuhan tersebut, coordinated effort - retailer menggabungkan semua strategi dan rencana untuk memaksimalkan efisiensi, value driven - retailer menawarkan nilai barang yang baik kepada konsumen dengan memberikan harga yang sesuai dengan level produk atau customer service, goal orientation - retailer menetapkan sebuah tujuan dan kemudian menggunakan strateginya untuk mencapai tujuan tersebut.

\section{Store-as-a-brand}

Lingkungan fisik dari toko, produk yang dijual, dan kualitas servis dari karyawan toko adalah faktor penting dalam penilaian oleh pelanggan terhadap store-as-a-brand (Burt \& Davies, 2010). Menurut Lefebvre \& Dubois (2013), retail brand adalah sebuah proses sistematik dengan tujuan untuk menciptakan sebuah nilai yang menjanjikan pengalaman yang unik untuk para pelanggan dari toko retail brand. Burt \& Davies (2010) menyatakan bahwa private brand yang ditawarkan oleh para retailer akan menjadi dasar sebuah image dan akan mempengaruhi retail brand dari toko tersebut.

Menurut Kumar \& Kim (2014), sebuah toko retail yang merupakan brand itu sendiri akan mampu untuk memperkuat hubungan emosional dan rasional dengan pelanggan, dimana hubungan rasional tercapai jika proses belanja mudah dan ada kesan baik dari pelanggan, sedangkan hubungan emosional akan tercapai jika proses belanja memberikan pengalaman yang menyenangkan bagi pelanggan. Menurut Floor dalam Kumar \& Kim (2014), sebuah toko retail dapat berubah dari yang awalnya hanya distributor produk menjadi sebuah brand kuat jika dapat mencapai hubungan rasional dan emosional dengan pelanggan, hal inilah yang akan membedakannya dari toko retail lainnya.

Menurut Floor para pelaku toko retail dapat mempraktekkan strategi storeas-a-brand (SBA) dengan fokus kepada faktor - faktor yang mempengaruhi indera dari pelanggan (contoh: atmospheric stimuli) dan varian produk (merchandise) didalam toko (dalam Kumar \& Kim, 2014). Menurut Kumar \& Kim (2014), variabel - variabel dari store atmosphere (social, design, dan ambient cues) dan merchandise berada dalam satu bagian, yaitu store environment.

Model Stimulus - Organism - Response Dalam konteks retail, faktor - faktor yang menentukan pengalaman dan respon 
pelanggan dapat dianalisa dari model stimulus - organism - response (SOR), dimana model ini menyatakan bahwa stimulus (faktor lingkungan) mempengaruhi organism (proses dalam pikiran pelanggan), dan akan menentukan response yang berupa perilaku pelanggan (Palacios et al., 2016).

Sherman et al., (1997) menyatakan bahwa stimulus adalah sesuatu yang mempengaruhi kondisi internal dari seseorang, organism adalah proses dan struktur internal yang menengahi antara stimuli kepada seseorang dan tindakan, reaksi, atau respon terakhir dari seseorang, dan response adalah tindakan atau reaksi terakhir dari seorang pelanggan, seperti sikap atau reaksi perilaku. Olahut et al., (2012) menyatakan bahwa atmospheric stimuli dapat mengakibatkan reaksi cognitive and affective yang spesifik, dan reaksi - reaksi ini dapat mengubah perilaku belanja.

Kumar \& Kim (2014) menyatakan bahwa ketika model ini diterapkan dalam konteks retail, stimuli (S) adalah store environmental cues yang mempengaruhi internal states (O) dari pelanggan, yang pada akhirnya akan mempengaruhi approach - avoidance response behavior (R) dari pelanggan. Dalam konteks retail, Schellinck menyatakan bahwa stimuli adalah store atmospheric cues yang mempengaruhi internal states dari pelanggan, cues didefinisikan sebagai karakteristik, peristiwa, atau objek yang berasal dari eksternal seseorang yang dapat ditentukan dan digunakan untuk mengelompokkan objek stimulus (dalam Kumar \& Kim, 2014).

Bagozzi mendefinisikan organism sebagai proses internal yang menengahi antara stimuli eksternal seseorang dan aksi, reaksi, atau respon terakhir dari orang tersebut, yang terdiri dari persepsi, perasaan, dan aktivitas berpikir (dalam Kumar \& Kim, 2014). Terdapat dua macam evaluasi internal dari seseorang yang terjadi karena lingkungan fisik, yaitu cognitive dan affective evaluation
(Proshansky et al., 1983). Cognitive evaluation diartikan sebagai proses persepsi dari konsumer, yang berasal dari proses pengolahan informasi dan inference theories (Bettman, 1979; Zeithaml, 1988). Menurut Bagozzi, affective evaluation diartikan sebagai emosi dan perasaan terhadap sebuah objek (dalam Kumar \& Kim, 2014). Russell \& Snodgrass juga menyatakan bahwa affective evaluation sebagai pertimbangan apakah suatu objek itu nyaman, menarik, bernilai, menyenangkan, atau lebih disukai (dalam Kumar \& Kim, 2014).

Chebat \& Michon membuktikan bahwa model dengan urutan cognition - emotion akan lebih baik dalam menjelaskan efek ambient scent on behavior dan memiliki model yang lebih baik daripada sebaliknya jika diterapkan di lingkungan mal atau pusat perbelanjaan. Response didefinisikan sebagai reaksi perilaku dari pelanggan seperti kepuasan, niat untuk berlangganan tetap, jumlah produk yang dibeli, dan jumlah uang yang dihabiskan di toko (Kim \& Damhorst, 2010).

Dalam konteks retail, response disebut sebagai approach or avoidance behavior (Kumar \& Kim, 2014). Dalam konteks retail, store atmosphere telah dibuktikan dapat mempengaruhi behavioral reactions secara tidak langsung melalui cognitive and affective evaluations (Law et al., 2012).

\section{Store Atmosphere}

Store atmosphere adalah komponen utama dari sebuah toko dan dapat didefinisikan sebagai "efek sensorik yang dominan yang diciptakan oleh desain, karakteristik fisik, dan merchandise dari sebuah toko" (Olahut et al., 2012). Hussain \& Ali (2015) menyatakan bahwa store atmosphere adalah istilah yang digunakan untuk menjelaskan perasaan kita terhadap pengalaman belanja yang mana tidak dapat dilihat, dan secara langsung dapat mempengaruhi keinginan dan keputusan pembelian. 
Store atmosphere terdiri dari beberapa cues, yang mempengaruhi evaluasi internal dari pelanggan: social, design, dan ambient cues (Baker dalam Kumar \& Kim, 2014). Baker et al., (1994) menyatakan bahwa komponen atmospheric dimensions adalah: ambient cues - musik, pencahayaan, dan bau; design cues penataan lantai, penataan dinding, penataan display, warna, kebersihan, ruang ganti, lorong, tanda; dan social cues karyawan toko.

Lin \& Chiang (2010) menjelaskan bahwa social cues mengacu kepada faktor tentang manusia, termasuk pelanggan dan karyawan, perilaku transaksi, tingkat kepadatan toko, keleluasaan pribadi, dan jalan untuk masuk dan keluar toko. Jumlah, tipe, dan perilaku dari pelanggan lain dan karyawan dalam lingkungan toko adalah elemen dari social cues (Baker et al., 1994). Baker et al., (1994) juga menyatakan bahwa karyawan di toko yang memiliki nama baik akan berpakaian rapi, baik dan bersikap kooperatif terhadap pelanggan, sedangkan karyawan di toko yang tidak memiliki nama baik akan berpakaian tidak rapi, sembarangan dan lebih bersikap tidak kooperatif terhadap pelanggan.

Design cues mengacu kepada perasaan estetika yang dapat dirasakan secara langsung oleh pelanggan, seperti corak, tata ruang, dan arsitektur ruangan (Chen \& Hsieh, 2010). Lin \& Chiang (2010) mengartikan design cues di lingkungan toko sebagai tata ruang, warna, kebersihan, tingkat kebisingan, ruang, dan lain - lainnya. Chen \& Hsieh (2010) menyatakan bahwa ambient cues adalah kondisi ambient yang dapat mempengaruhi pelanggan potensial, seperti temperature ruangan, musik, kebisingan, dan cahaya. Olahut et al., (2012) menyatakan bahwa ambient cues seperti aroma udara di toko memiliki peran signifikan ketika pelanggan akan mengevaluasi toko.

Newman \& Patel (2004) menyatakan bahwa merchandise di toko yang cepat diperbarui sesuai dengan gaya terkini akan menciptakan competitive advantage untuk toko tersebut. Menurut Newman \& Patel (2004), merchandise cues seperti macam pilihan baju yang ada di toko dianggap sebagai faktor penting yang berkontribusi ketika pelanggan mengevaluasi sebuah toko.

Menurut Olahut et al., (2012), merchandise dalam retail dapat membentuk perilaku pelanggan terhadap toko tersebut.

Bagi para pelaku retail store-as-a-brand, store atmospheric cues, bersama dengan merchandise yang eksklusif, menjadi alasan utama bagi pelanggan untuk mengunjungi sebuah toko karena tidak dapat ditemukan di toko - toko lainnya (Kumar \& Kim, 2014).

\section{Customer Evaluation}

Berdasarkan penelitian dari Bone \& Ellen (1999), Chebat \& Michon (2003) dan Spangenberg et al., (1996), ditemukan bahwa efek dari atmospheric cues pada emotions terjadi secara tidak langsung melalui cognition. Menurut Lazarus, dibutuhkan keadaan cognition untuk menghasilkan emotions (dalam Kumar \& Kim, 2014). Menurut Chebat \& Michon (2003), dengan penerapan di lingkungan mal atau pusat perbelanjaan, model dengan urutan cognition - emotion akan menjelaskan efek ambient scent on behavior secara lebih baik dan memiliki model yang lebih baik daripada sebaliknya.

Menurut Palacios et al., (2016) reaksi cognitive adalah konfirmasi baik atau tidak baik dari evaluasi harapan dan kualitas. Chen \& Hsieh (2011) membagi cognitive evaluation dari pelanggan menjadi tiga yaitu: (1) komponen produk (konsistensi kualitas produk, karakteristik produk, macam jenis produk, dan kemudahan pemakaian produk), (2) komponen servis toko (keandalan dan kecepatan dalam pelayanan, bantuan teknikal, dan pelayanan yang cepat), (3) komponen promosi (store image, 
corporate identity, hubungan personal, dan keandalan dari supplier produk).

Palacios et al., (2016) menyimpulkan bahwa affective evaluation adalah respon seseorang yang meliputi emosi, suasana hati, dan perasaan. Menurut Russell dan Snodgrass, affective evaluation adalah sebuah pertimbangan apakah suatu objek itu nyaman, menarik, bernilai, menyenangkan, atau lebih disukai (dalam Kumar \& Kim, 2014).

Approach - Avoidance Behavior Donovan \& Rossiter (1982) menyatakan bahwa approach - avoidance behavior adalah semua respon seseorang terhadap sebuah lingkungan. Mehrabian \& Russel menyimpulkan bahwa approach behavior adalah keinginan untuk bertahan di toko, lanjut berbelanja, dan tinggal untuk waktu yang relatif lebih lama, sebaliknya, avoidance behavior adalah reaksi negatif seperti keinginan untuk pergi dari toko dan tidak kembali lagi (dalam Kumar \& Kim, 2014). Law et al. (2012) menyatakan bahwa dalam konteks retail, store atmosphere telah dibuktikan dapat mempengaruhi behavioral reactions secara tidak langsung melalui cognitive and affective evaluations.

\section{PENGEMBANGAN HIPOTESIS}

Menurut Singh (2006), ditemukan persepsi positif dari social cues terhadap cognitive evaluations toward store. Baker et al., (1994) menjelaskan bahwa selalu tersedianya karyawan yang melayani pelanggan di toko juga merupakan faktor penting yang mempengaruhi cognitive evaluations toward store. Spangenberg et al., (1996) menemukan bahwa kekacauan dalam lingkungan toko akan berpengaruh negatif terhadap evaluasi pelanggan mengenai pelayanan toko.

Kumar \& Kim (2014) menyatakan bahwa design cues yang ada di toko retail akan meningkatkan cognitive evaluations toward store. Baker et al., (1994) juga menjelaskan bahwa store's interior yang merupakan bagian dari design cues adalah salah satu yang terpenting dalam mempengaruhi cognitive evaluations toward store. Kumar \& Kim (2014) juga menyimpulkan bahwa ambient cues penting untuk meningkatkan cognitive evaluations toward store.

Chebat \& Michon (2003) menyatakan bahwa para pelaku retail harus mengatur ambient cues di toko dengan sebaik - baiknya karena ambient cues adalah salah satu teknik paling murah yang dapat digunakan untuk meningkatkan evaluasi positif dari pelanggan. Kemudian, jika pelanggan menganggap bahwa sebuah toko memiliki merchandise cues yang baik, maka hal tersebut akan berpengaruh positif terhadap cognitive evaluations toward merchandise (Kumar \& Kim, 2014). Newman \& Patel (2004) juga menyatakan bahwa sebuah toko dengan pilihan merchandise yang bermacammacam dan terkini akan berpengaruh positif terhadap cognitive evaluations toward merchandise.

H1a: Persepsi dari social cues dalam toko ritel mempengaruhi cognitive evaluations toko ritel secara signifikan.

H1b: Persepsi dari design cues dalam toko ritel mempengaruhi cognitive evaluations toko ritel secara signifikan.

H1c: Persepsi dari ambient cues dalam toko ritel mempengaruhi cognitive evaluations toko ritel secara signifikan.

H1d: Persepsi dari merchandise cues dalam toko ritel mempengaruhi cognitive evaluations merchandise toko ritel secara signifikan.

Kumar \& Kim (2014) menjelaskan bahwa ketika seseorang memasuki sebuah toko, maka akan muncul stimuli yang akan membentuk cognitive evaluations toward store yang akan berpengaruh terhadap affective evaluations toward store. Kemudian, jika pelanggan memiliki cognitive evaluations toward merchandise yang positif di toko tersebut, maka hal ini akan secara positif mempengaruhi affective 
evaluations toward merchandise (Kumar \& Kim, 2014).

Sherman et al., (1997) menyatakan bahwa cognitive evaluations dari pelanggan terhadap faktor - faktor yang ada di dalam sebuah toko seperti pencahayaan, warna, merchandise, dan karyawan akan memiliki pengaruh penting terhadap emotional evaluation.

H2a: Cognitive evaluations toko ritel mempengaruhi affective evaluations toko ritel secara signifikan.

H2b: Cognitive evaluations merchandise toko ritel mempengaruhi affective evaluations merchandise toko ritel secara signifikan.

Russell \& Snodgrass menyatakan bahwa affective evaluations adalah sebuah pertimbangan apakah suatu objek itu nyaman, menarik, bernilai, menyenangkan, atau lebih disukai (dalam Kumar \& Kim, 2014). Sedangkan, menurut Donovan \& Rossiter (1982), approach - avoidance behavior adalah respon seseorang terhadap sebuah lingkungan. Dalam penelitiannya, Kumar \& Kim (2014) menyatakan bahwa affective evaluations toward store akan berpengaruh positif terhadap approach behavior. Dan juga, pelanggan yang memiliki affective evaluations toward merchandise yang positif seperti kesukaan dengan produk yang dicari akan berpengaruh positif terhadap approach behavior, yaitu pelanggan akan menghabiskan waktu dan uang lebih banyak di toko.

Spangenberg et al., menyatakan bahwa lingkungan toko yang menghasilkan situasi menyenangkan bagi pelanggan akan menghasilkan approach behavior, sedangkan lingkungan toko yang menghasilkan situasi tidak menyenangkan bagi pelanggan akan menghasilkan avoidance behavior. Sweeney \& Wyber (2002) menyatakan bahwa pelanggan yang merasa senang secara emosional akan sangat berpengaruh terhadap approach - avoidance behavior terhadap suatu toko, dan akan berpotensi untuk menghabiskan uang lebih banyak di toko.

Wakefield \& Baker (1998) menyatakan bahwa semakin senang seorang pelanggan secara emosional di dalam sebuah toko, maka semakin lama waktu yang akan dihabiskan pelanggan di dalam toko tersebut, bahkan melebihi rencana awal sang pelanggan tersebut.

H3a: Affective evaluations toko ritel mempengaruhi approach behavior secara signifikan.

H3b: Affective evaluations merchandise toko ritel mempengaruhi approach behavior secara signifikan.

Bitner (1992) menyatakan bahwa reaksi cognitive adalah keyakinan seseorang tentang sebuah toko dan karyawan serta produk yang ada di dalam toko tersebut. Menurut Spangenberg et al., (1996), approach - avoidance behavior adalah dua respon yang kontras dari seseorang terhadap sebuah lingkungan. Kumar \& Kim (2014) menyatakan bahwa cognitive evaluations toward store yang positif dari pelanggan akan berpengaruh terhadap approach behavior, yaitu pelanggan akan menghabiskan waktu dan uang lebih banyak di toko. Dan juga, bila pengaturan produk di toko baik dan teratur, juga toko menyediakan varian merchandise yang banyak, maka pelanggan akan puas dengan toko tersebut dan akan menghabiskan waktu dan uang lebih banyak, maka dapat disimpulkan bahwa cognitive evaluations toward merchandise yang positif akan berpengaruh terhadap approach behavior.

Sweeney \& Wyber (2002) menyatakan bahwa karyawan dan pelanggan di dalam sebuah toko akan melakukan evaluasi dan respon secara cognitive, yang mana akan menjadi faktor yang akan mempengaruhi approach avoidance behavior. 
H3c: Cognitive evaluations toko RITEL mempengaruhi approach behavior secara signifikan.

H3d: Cognitive evaluations merchandise toko ritel mempengaruhi approach behavior secara signifikan.

Berdasarkan penelitian oleh Spangenberg et al., (1996), evaluasi affective terhadap lingkungan toko secara keseluruhan dan evaluasi affective terhadap produk membentuk sebuah evaluasi internal. Menurut Kumar \& Kim (2014), para pelaku retail ingin menciptakan holistic image dimana pelanggan tidak melihat ada perbedaan signifikan antara toko dan produk yang dijual, yaitu affective evaluations toward store dan affective evaluations toward merchandise tidak akan berbeda secara signifikan.

Burt \& Davies (2010) menyatakan bahwa store-as-a-brand adalah keadaan toko dimana pelanggan merasakan pengalaman menarik ketika berbelanja di suatu toko, dan mereka menganggap bahwa toko itu adalah produk retail itu sendiri. Dengan menggunakan strategi store-as-abrand, para pelaku retail ingin menciptakan kesan pada pelanggan bahwa toko dan produk yang dijual adalah merupakan satu kesatuan dan bukan merupakan dua hal yang berbeda, dan seharusnya akan berpengaruh secara statistik, yaitu cognitive evaluations toward store dan cognitive evaluations toward merchandise tidak akan berbeda secara signifikan (Kumar \& Kim, 2014).

H4a1: Affective evaluations toko ritel mempengaruhi affective evaluations merchandise toko ritel secara signifikan.

H4a2: Affective evaluations merchandise toko ritel mempengaruhi affective evaluations toko ritel secara signifikan.

H4b1: Cognitive evaluations toko ritel mempengaruhi cognitive evaluations merchandise toko ritel secara signifikan.

H4b2: Cognitive evaluations merchandise toko ritel mempengaruhi cognitive evaluations toko ritel secara signifikan.

\section{METODE}

Desain Penelitian

Penelitian ini dilakukan dengan pendekatan kuantitatif. Tujuan dari penelitian ini adalah uji hipotesa. Penelitian ini menggunakan confirmatory factor analysis (CFA) dan structural equation model (SEM) untuk menguji hubungan kausal diantara variabel. Desain dari penelitian ini adalah cross sectional. Penelitian ini menggunakan interval scale. Teknik skala yang digunakan adalah 5Point Likert Scale. Tabel 1 menunjukkan indikator untuk setiap variabel.

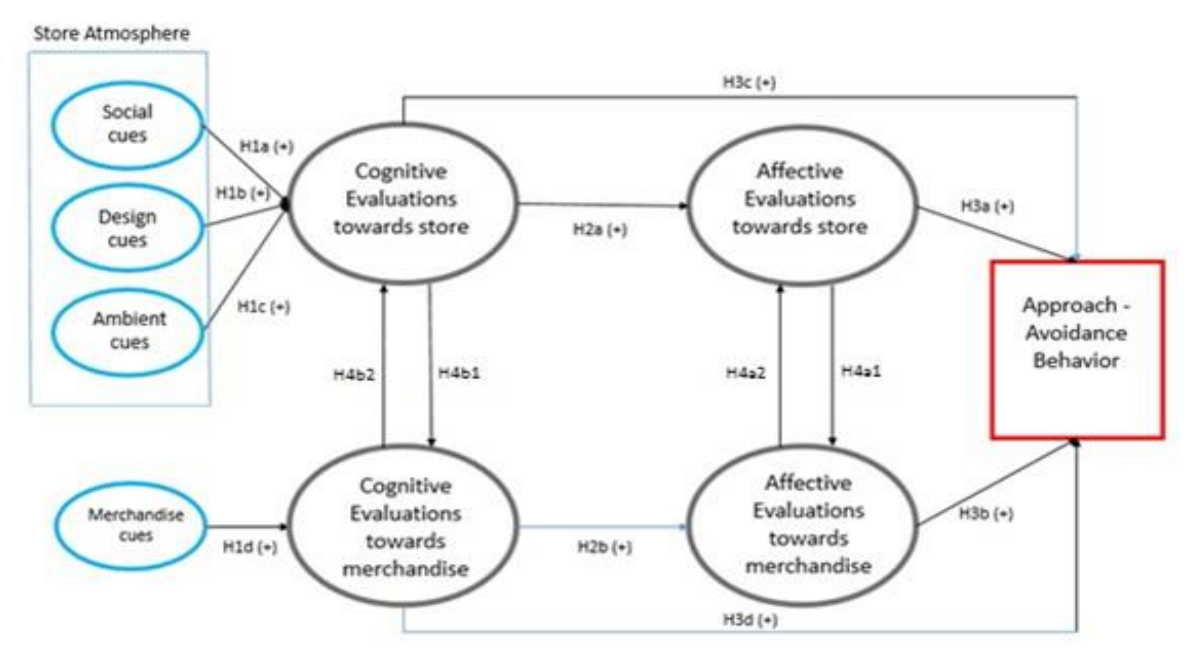

Gambar 1. Kerangka teoritis. 
Tabel 1. Indikator Pengukuran

\begin{tabular}{|c|c|c|c|}
\hline Variable & Indicator & $\begin{array}{l}\text { Factor } \\
\text { Loading }\end{array}$ & $\begin{array}{l}\text { Cronbach } \\
\text { Alpha }\end{array}$ \\
\hline \multirow[t]{3}{*}{ Social cue } & Keramahan & 0.863 & \multirow[t]{3}{*}{0.798} \\
\hline & $\begin{array}{l}\text { Keinginan } \\
\text { Membantu }\end{array}$ & 0.854 & \\
\hline & Pemahaman Produk & 0.816 & \\
\hline \multirow[t]{4}{*}{ Design cue } & Komposisi Warna & 0.816 & \multirow[t]{4}{*}{0.837} \\
\hline & Kombinasi Warna & 0.787 & \\
\hline & $\begin{array}{l}\text { Visual } \\
\text { Merchandising }\end{array}$ & 0.729 & \\
\hline & Dekorasi & 0.782 & \\
\hline \multirow[t]{4}{*}{ Ambient cue } & Tata Cahaya & 0.705 & \multirow[t]{4}{*}{0.776} \\
\hline & Tata Suara & 0.834 & \\
\hline & Jenis Musik & 0.780 & \\
\hline & Intensitas Musik & 0.772 & \\
\hline \multirow[t]{3}{*}{ Merchandise Cue } & Kualitas Produk & 0.835 & \multirow[t]{3}{*}{0.772} \\
\hline & Kuantitas Produk & 0.829 & \\
\hline & Mode Produk & 0.826 & \\
\hline \multirow[t]{3}{*}{ Cognitive evaluation toward store } & Kesan Toko & 0.861 & \multirow[t]{3}{*}{0.900} \\
\hline & Sikap Toko & 0.873 & \\
\hline & Penilaian Toko & 0.902 & \\
\hline \multirow{3}{*}{$\begin{array}{l}\text { Cognitive evaluations toward } \\
\text { merchandise }\end{array}$} & Penilaian Produk & 0.883 & \multirow[t]{3}{*}{0.903} \\
\hline & Sikap Produk & 0.890 & \\
\hline & Kesan Produk & 0.857 & \\
\hline \multirow[t]{3}{*}{ Affective evaluations toward store } & Suasana Toko & 0.863 & \multirow[t]{3}{*}{0.826} \\
\hline & Kenyamanan Toko & 0.906 & \\
\hline & Keunikan Toko & 0.821 & \\
\hline \multirow{3}{*}{$\begin{array}{l}\text { Affective evaluations toward } \\
\text { merchandise }\end{array}$} & Keunikan Produk & 0.872 & \multirow[t]{3}{*}{0.872} \\
\hline & Keragaman Produk & 0.827 & \\
\hline & Ketepatan Produk & 0.880 & \\
\hline \multirow[t]{4}{*}{ Approach Avoidance Behavior } & $\begin{array}{l}\text { Kenikmatan } \\
\text { Belanja }\end{array}$ & 0.811 & \multirow[t]{4}{*}{0.798} \\
\hline & Suasana Belanja & 0.819 & \\
\hline & $\begin{array}{l}\text { Kenyamanan } \\
\text { Belanja }\end{array}$ & 0.790 & \\
\hline & Kesesuaian Belanja & 0.765 & \\
\hline
\end{tabular}

\section{Metode Pengumpulan Data}

Penelitian ini menggunakan data primer yang dikumpulkan pada tahun 2016 dan sekunder yang dikumpulakn untuk menggambarkan kondisi ritel di Indonesia tiga tahun terakhir. Data primer adalah kuesioner yang didapatkan langsung dari responden dan data sekunder adalah data yang didapatkan dari penelitian sebelumnya yang berupa jurnal, buku, internet, dan laporan. Dalam penelitian ini, peneliti menggunakan non - probability sampling dan purposive sampling. Pemilihan metode sampling ini dilakukan untuk mempercepat proses pengambilan data sehingga hasilnya dari penelitian ini dapat segera diaplikasikan sehingga toko ritel dapat cepat beradaptasi dengan perkembangan industri ritel yang sangat cepat. Responden dalam penelitian ini 
adalah pelanggan yang sudah pernah mengunjungi toko ritel di Jakarta yang terdapat di mal: Grand Indonesia, Central Park, Senayan City, Kota Kasablanka, dan Pondok Indah Mall. Peneliti melakukan kontrol data dengan kriteria utama responden sebagai berikut: (1) Jenis kelamin laki - laki, (2) Usia 18 - 35 tahun, dan (3) Pernah mengunjungi atau membeli produk di toko ritel di Jakarta dalam 6 bulan terakhir (periode 10 November 2015 - 10 Mei 2016). Dari total 5 mall yang menjadi obyek penelitian ini, didapatkan total responden sejumlah 338. Hair et al. (2010) menyatakan bahwa jumlah sampel dengan jumlah minimal $5-10 \times$ jumlah indikator sudah cukup untuk meneliti model yang baik.

Persentase profil responden yang terbesar adalah: umur $21-25$ tahun (59.5\%), pengeluaran per bulan $\mathrm{Rp}$ 2.000.001 - Rp 3.000.000 (40.5\%), terakhir mengunjungi ritel pada 1 bulan terakhir $(40.5 \%)$, jumlah belanja dalam sekali kunjungan adalah 1 pcs $(45.3 \%)$, dan produk yang paling sering dibeli adalah baju (72.5\%).

\section{Analisa Data}

Confirmatory factor analysis (CFA) digunakan dalam penelitian ini untuk menguji validitas dan reliabilitas. Sebuah item instrumen penelitian dinyatakan valid apabila factor loading item tersebut berada di angka 0.5 atau lebih (Hair, 2010). Ditunjukkan pada tabel 1, bahwa factor loading untuk seluruh indikator variabel berada di atas angka 0.5 , maka dapat disimpulkan bahwa seluruh indikator sudah valid untuk mengukur variabel penelitian. Hair (2010) menyatakan bahwa Cronbach's Alpha dengan nilai minimal 0.7 dapat dikatakan memiliki reliabilitas yang konsisten. Dapat dilihat pada tabel 1, bahwa Cronbach's Alpha untuk semua variabel berada diatas angka 0.7 .

Hasil uji Structural Equation Modeling (SEM) dilakukan dengan menggunakan software IBM AMOS versi 21. Dari hasil uji SEM, didapatkan hasil model pengukuran ini layak untuk digunakan dan masuk dalam kategori moderate fit berdasarkan normed ChiSquare sebesar 3,14, Root Mean Square Error of Approximation (RMSEA=0,08), Comparative Fit Index (CFI=0,849), dan Goodness Fit of Index (GFI=0,772).

Semua angka factor loading yang signifikan (>0.5), menunjukkan bahwa seluruh indikator memiliki hubungan signifikan dengan variabel terkait. Berdasarkan tabel 2, hasil uji SEM menunjukkan bahwa dari komponen store atmosphere, social cues $(\beta=0.38)$ adalah prediktor terkuat terhadap cognitive evaluations toward store. Menurut Hair et al. (2010), sebuah hipotesis dinyatakan diterima jika $t$-value /Critical Ratio = \pm 1.96 dan $\mathrm{p}<0.05$.

Berdasarkan Tabel 2, hasil uji SEM menyatakan bahwa seluruh hipotesis memiliki pengaruh yang signifikan, kecuali H3b, H3d, dan H4a2. Ditunjukkan pada tabel 2, bahwa hasil uji hipotesis untuk H3b: Affective evaluations toward merchandise $\rightarrow$ Approach-Avoidance behavior tidak signifikan $(\beta=-0.10 ; t=-$ $0.631 ; p=0.528), \quad \mathrm{H} 3 \mathrm{~d}:$ Cognitive evaluations toward merchandise $\rightarrow$ Approach - Avoidance behavior tidak signifikan $(\beta=-0.03 ; t=-0.287 ; p=$ 0.774), dan H4a2: Affective evaluations toward merchandise $\rightarrow$ Affective evaluations toward store tidak signifikan $(\beta=-0.16 ; t=-0.787 ; p=0.431)$.

Berdasarkan hasil analisa, ditolaknya $\mathrm{H} 3 \mathrm{~b}$ dikarenakan bahwa apparel bukanlah produk dengan high involvement (contoh: sepeda motor Harley), karena itu tidak ada ikatan emosional dan pelanggan hanya membeli produk apparel ketika ada kebutuhan.

Sedangkan H3d ditolak karena:

Display produk dari RITEL yang bagus dan terkesan mewah mencerminkan produk yang ditampilkan memiliki harga yang mahal, sehingga para pelanggan cenderung tidak jadi masuk toko (avoidance behavior), dan (2) Responden dalam penelitian ini adalah laki - laki yang 
lebih memperhatikan pelayanan dari pegawai toko, sedangkan untuk produk baik maka mereka akan melakukan apparel, jika produk dirasa sudah cukup pembelian.

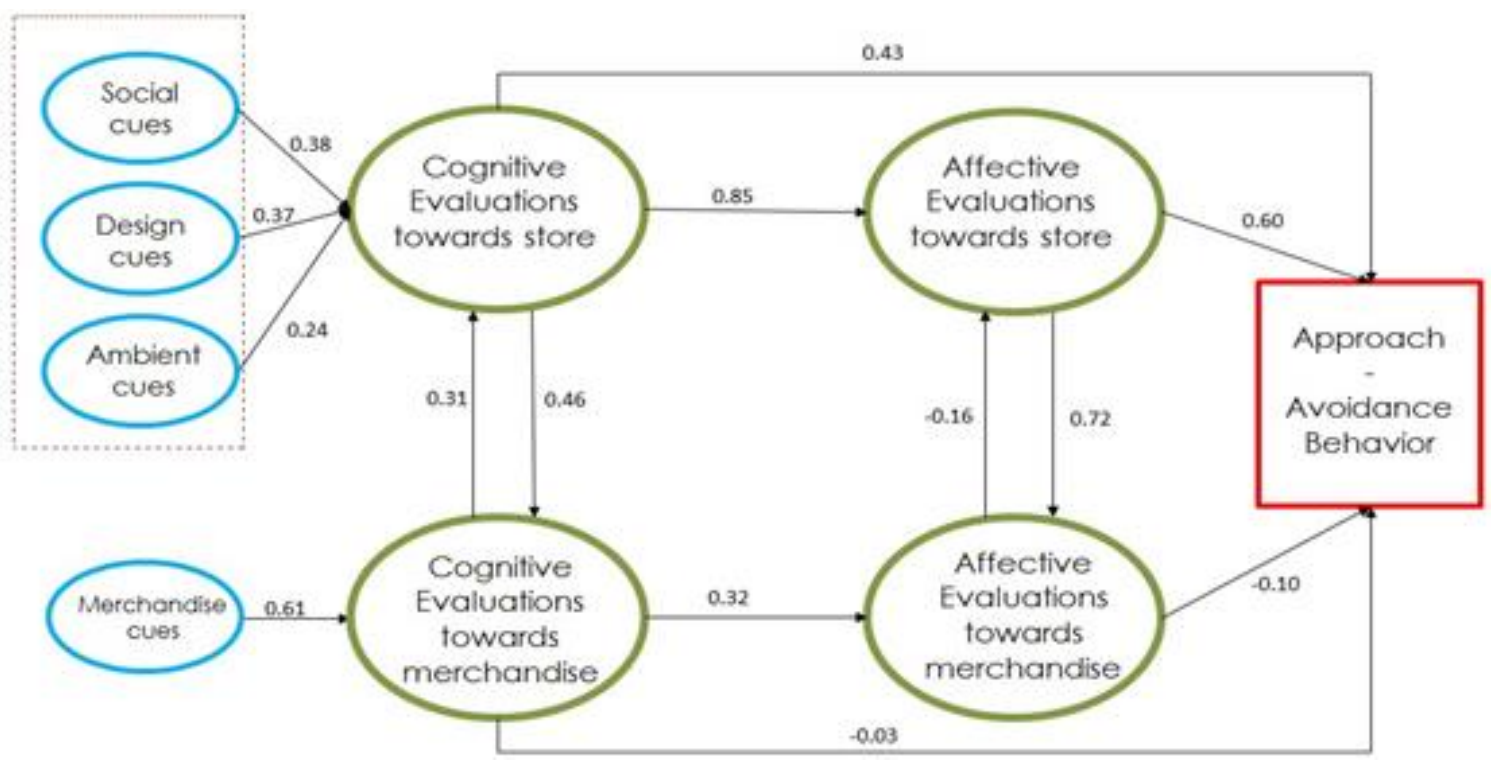

Gambar 2. Model struktural.

Tabel 2. Hasil Uji SEM

\begin{tabular}{|c|c|c|c|c|c|}
\hline & & Hipotesis & $\begin{array}{c}\text { Estimate } \\
(\boldsymbol{\beta})\end{array}$ & $\begin{array}{l}\text { Tvalue/ } \\
\text { C.R. }\end{array}$ & $\mathbf{P}$ \\
\hline \multirow[t]{4}{*}{ H1 } & $\mathrm{a}$ & Social cues $\rightarrow$ cognitive evaluations toward store & 0.38 & 7.277 & $* * *$ \\
\hline & $\mathrm{b}$ & $\begin{array}{l}\text { Design cues } \rightarrow \text { cognitive evaluations toward } \\
\text { store }\end{array}$ & 0.37 & 7.334 & $* * *$ \\
\hline & $\mathrm{c}$ & $\begin{array}{l}\text { Ambient cues } \rightarrow \text { cognitive evaluations toward } \\
\text { store }\end{array}$ & 0.24 & 5.21 & $* * *$ \\
\hline & $\mathrm{d}$ & $\begin{array}{l}\text { Merchandise cues } \rightarrow \text { cognitive evaluations } \\
\text { toward merchandise }\end{array}$ & 0.61 & $\begin{array}{c}10.07 \\
4\end{array}$ & $* * *$ \\
\hline \multirow[t]{2}{*}{$\mathbf{H 2}$} & $\mathrm{a}$ & $\begin{array}{l}\text { Cognitive evaluations toward store } \rightarrow \text { affective } \\
\text { evaluations toward store }\end{array}$ & 0.85 & 4.921 & $* * *$ \\
\hline & $\mathrm{b}$ & $\begin{array}{c}\text { Cognitive evaluations toward } \\
\text { merchandise } \rightarrow \quad \text { affective } \\
\text { evaluations toward merchandise }\end{array}$ & 0.32 & 5.609 & $* * *$ \\
\hline \multirow[t]{3}{*}{ H3 } & $\mathrm{a}$ & $\begin{array}{l}\text { Affective evaluations toward store } \rightarrow \text { approach }- \\
\text { avoidance behavior }\end{array}$ & 0.60 & 3.574 & $* * *$ \\
\hline & $\mathrm{b}$ & $\begin{array}{l}\text { Affective evaluations toward merchandise } \rightarrow \\
\text { approach avoidance behavior }\end{array}$ & -0.10 & $\begin{array}{c}- \\
0.631\end{array}$ & 0.528 \\
\hline & $\mathrm{c}$ & $\begin{array}{l}\text { Cognitive evaluations toward store } \rightarrow \text { approach }- \\
\text { avoidance behavior }\end{array}$ & 0.43 & 3.827 & $* * *$ \\
\hline
\end{tabular}


$\mathrm{d} \quad$ Cognitive evaluations toward merchandise $\rightarrow \quad-0.03 \quad-\quad 0.774$ approach avoidance behavior

0.287

\begin{tabular}{|c|c|c|c|c|c|c|}
\hline \multirow[t]{2}{*}{ H4 } & a1 & \multicolumn{2}{|c|}{$\begin{array}{l}\text { Affective evaluations toward store } \rightarrow \text { affective } \\
\text { evaluations toward merchandise }\end{array}$} & 0.72 & 8.137 & $* * *$ \\
\hline & $\mathrm{a} 2$ & \multicolumn{2}{|c|}{$\begin{array}{l}\text { Affective evaluations toward merchandise } \rightarrow \\
\text { affective evaluations toward store }\end{array}$} & -0.16 & $\begin{array}{c}- \\
0.787\end{array}$ & 0.431 \\
\hline \multirow[t]{2}{*}{ H4 } & b1 & $\begin{array}{l}\text { Cognitive evaluations towa } \\
\text { evaluations toward merch }\end{array}$ & $\begin{array}{l}\text { store } \rightarrow \text { cognitive } \\
\text { dise }\end{array}$ & 0.46 & 5.285 & $* * *$ \\
\hline & b2 & $\begin{array}{c}\text { Cognitive evaluations } \\
\text { merchandise } \rightarrow \\
\text { evaluations toward store }\end{array}$ & $\begin{array}{l}\text { toward } \\
\text { cognitive }\end{array}$ & 0.31 & 8.025 & $* * *$ \\
\hline
\end{tabular}

Catatan: ${ }^{* * *} p<0,01$

Bagus atau tidaknya produk tidak secara signifikan mempengaruhi keinginan mereka untuk kembali lagi ke toko (approach - avoidance behavior). Dan, ditolaknya $\mathrm{H} 4 \mathrm{a} 2$ disebabkan karena pelanggan pria menilai sebuah toko tidak dipengaruhi oleh kualitas sebuah produk, karena antara produk dan toko tidak ada hubungannya.

Dalam konsep store-as-a-brand, kedua hipotesa $\mathrm{H} 4 \mathrm{a} 1$ dan $\mathrm{H} 4 \mathrm{a} 2$ harus signifikan, dan juga kedua hipotesa H4b1 dan $\mathrm{H} 4 \mathrm{~b} 2$ harus signifikan. Karena $\mathrm{H} 4 \mathrm{a} 2$ tidak signifikan, maka dapat disimpulkan bahwa pelanggan tidak melihat toko RITEL dan produknya sebagai satu kesatuan.

\section{KESIMPULAN DAN IMPLIKASI Kesimpulan}

Berdasarkan hasil analisa, dapat disimpulkan bahwa H1a, H1b, H1c, H1d, $\mathrm{H} 2 \mathrm{a}, \mathrm{H} 2 \mathrm{~b}, \mathrm{H} 3 \mathrm{a}, \mathrm{H} 3 \mathrm{c}, \mathrm{H} 4 \mathrm{a} 1, \mathrm{H} 4 \mathrm{~b} 1$, dan H4b2 diterima. Sedangkan H3b, H3d, dan $\mathrm{H} 4 \mathrm{a} 2$ ditolak.

\section{Implikasi}

Penelitian ini menawarkan beberapa saran dan implikasi yang dapat menjadi masukan untuk toko ritel di Jakarta untuk menarik lebih banyak pelanggan.

Fasilitas toko: (1) menambah jumlah kamar pas dan digital display monitor, (2) menempatkan PIC di lorong kamar pas, (3) memperbesar tampilan size baju di rak, (4) menyediakan papan keterangan tentang produk dan seluruh ukuran baju dan celana disamping rak, (5) rutin dalam maintenance furniture toko.

Pencahayaan dapat menggunakan lampu sorot dengan warna berbeda-beda yang difokuskan pada produk display. Cahaya lampu toko harus disesuaikan dengan keadaan. Musik harus mengikuti trend terkini dan volume disesuaikan dengan tingkat keramaian toko.

Produk display ditempatkan pada posisi strategis yang menarik perhatian pengunjung mal yang lewat di depan toko dan harus selalu dijaga kualitasnya dengan penjadwalan maintenance. Menambahkan variasi produk seperti kaos ONeck, VNeck, dan celana regular fit. Menyesuaikan desain produk dengan trend di pasaran seperti variasi baju dengan tema sepakbola dan superhero.

Mengadakan pelatihan kerja dan seminar mengenai visi misi perusahaan untuk karyawan baru dan lama yang dapat diadakan sebelum masuk bekerja atau 6 bulan sekali. Meningkatkan koordinasi antar PIC per section dan juga dengan kasir melalui latihan atau instruksi langsung dari manajer toko.

Menurunkan harga produk agar dapat lebih kompetitif dengan produk sejenis. Mengadakan kampanye marketing seperti $50 \%$ discount atau Buy 2 Get 1 . Agar dapat menciptakan hubungan emosional yang kuat dengan pelanggan, toko ritel dapat menggunakan foto model 
artis nasional atau model anonim dengan tubuh proposional untuk dipajang di store wallpaper, dimana para bintang ini nantinya akan dihadirkan dalam kampanye marketing toko ritel seperti talkshow dan fashion show.

Seperti yang sudah dibahas pada hasil analisa sebelumnya, bahwa pelanggan tidak melihat toko ritel sebagai store-as-a-brand, dimana toko dan produk tidak dilihat sebagai satu kesatuan, maka toko ritel dapat menerapkan beberapa hal berikut agar sukses menerapkan konsep store-as-a-brand: (1) membuat suasana toko menarik dan tidak terkesan mahal dengan menurunkan harga produk, memasang banner diskon, dan rutin berpartisipasi dalam midnight sale, (2) menyediakan konsultan fashion pria dan album fashion pria dari masa ke masa agar dapat menjadi referensi bagi pelanggan, (3) membuat desain toko yang maskulin dengan memasang foto model artis nasional atau model anonim dengan postur tubuh proposional sebagai store wallpaper, menyediakan digital display monitor untuk pelanggan melihat preview baju atau celana di tubuh mereka.

Diharapkan saran dan implikasi ini dapat diterapkan di seluruh cabang toko ritel di Jakarta dan menjadi standar toko ritel agar menjadi ciri yang unik dibandingkan kompetitor.

\section{Pembatasan Penelitian dan Saran Untuk Penelitian Berikutnya}

Penelitian ini hanya meneliti sembilan variabel, yaitu: Social cues, Design cues, Ambient cues, Merchandise cues, Cognitive Evaluations toward store, Cognitive Evaluation toward merchandise, Affective Evaluations toward store, Affective Evaluations toward merchandise, dan Approach or avoidance behavior.

Cakupan responden penelitian adalah pelanggan toko retail apparel di Jakarta dengan jenis kelamin pria. Penelitian hanya dilakukan terhadap toko retail apparel di Jakarta. Penelitian berikutnya disarankan untuk: (1) dilakukan pada toko retail apparel yang lain di kota yang berbeda, (2) menambahkan variabel Purchase Intention, (3) menambahkan jumlah responden, (4) memperbaiki tata kata kuesioner agar mendapat hasil yang lebih akurat.

\section{DAFTAR PUSTAKA}

1. Ailawadi, K., \& Keller, K., L.. Understanding retail branding: conceptual insights and research priorities. Journal of Retailing. Vol. 80, 2004. 331-342.

2. Azevodo, S., Pereira, M., Ferreira, J., \& Pedroso, V. Consumer Buying behaviour in Fashion Retailing: Empirical Evidencies. Munich Personal RePEc Archive. 2008

3. Baker, J., Grewal, D., \& Parasuraman, A. The influence of store environment on quality inferences and store image. Journal of the Academy of Marketing Science. 1994. Vol. 22, 328- 339.

4. Berman, B., \& Evans, J., R. Retail Management: A Strategic Approach. $10^{\text {th }}$ Edition. Prentice Hall. 2007

5. Bitner, M., J. Servicescapes: the impact of physical surroundings on customers and employees. Journal of Marketing. Vol. 56 (2), 1992. 57-65.

6. Bone, F., P., \& Ellen, P., S.. Scents in the marketplace: explaining a fraction of olfaction. Journal of Retailing. Vol. 75. 1999. 243-262.

7. Burt, S., \& Davies, K. From the retail brand to the retailer as a brand: themes and issues in retail branding research. International Journal of Retail and Distribution Management. Vol. 38, 2010. 865-878.

8. Chebat, J.-C., \& Michon, R. Impact of ambient odors on mall shoppers' emotions, cognition, and spending: a test of competitive causal theories. Journal of Business Research. Vol. 56, 2003. 529-539. 
9. Chen, H., S., \& Hsieh, T.. The effect of atmosphere on customer perceptions and customer behavior responses in chain store supermarkets. African Journal of Business Management. Vol. 52011 (24).

10. Cheng, M. 2015-16 Outlook for the Retail and Consumer Products Sector in Asia, 21. 2014.

11. Donovan, R., J., \& Rossiter, J., R. Store atmosphere: an environmental psychology approach. Journal of Retailing. Vol. 58, 1982.34-47.

12. Eroglu, S., A., Machleit, K., A., \& Davis, L., M. Empirical testing of a model of online store atmospherics and shopper responses.

13. Psychology and Marketing. Vol. 20, 2003. 139-150.

14. Hair, J. F. Jr., Black, W. C., Babin, B. J., \& Anderson, R. E. Multivariate Data Analysis, $7^{\text {th }}$ Ed. New Jersey: Prentice Hall, Inc. 2010

15. Hussain, R., \& Ali, M. Effect of Store Atmosphere on Consumer Purchase Intention. International Journal of Marketing Studies. Vol. 7 (2). 2015

16. Kim, J., \& Damhorst, M., L. Effects of level of Internet retailer's service quality on perceived apparel quality, perceived service quality, perceived value, satisfaction, and behavioral intentions toward an Internet retailer. Clothing and Textile Research Journal. Vol. 28, 2010. 56-73.

17. Kumar, A., \& Kim, Y., K. The storeas-abrand strategy: The effect of store environment on customer responses. Journal of Retailing and Consumer Services. Vol. 21, 2014. 685-695.

18. Law, D., Wong, C., W., \& Yip, J. How does visual merchandising affect consumer affective response? An intimate apparel experience. European
Journal of Marketing. Vol. 46, 2012.p112- 133.

19. Lefebvre, C., M., \& Dubois, P., L. Retail branding as a value creation process: managerial and research priorities. Journal of Product \& Brand Management. 2013. 384-392.

20. Lin, M., Q., \& Chiang, Y., F. The Influence of Store Environment on Perceived Experiential Value and Behavior Intention. Asia Pacific Management Review. Vol. 15 (2), 2010. $281-299$.

21. Machleit, K., A., Eroglu, S., A., \& Mantel, S., P. Perceived retail crowding and shopping satisfaction: what modifies this relationship? Journal of Consumer Psychology. Vol. 9 (1), 2000. 29-42.

22. Mattila, A., S., \& Wirtz, J. Congruency of scent and music as a driver of instore evaluations and behavior. Journal of Retailing. Vol. 77, 2001. 273-289.

23. Olahut, M., R., El-Murad, J., \& Plaias, I. (2012). Store atmosphere: Conceptual Issues and Its Impact on Shopping Behavior. International Conference "Marketing - from information to decision" 5th Edition.

24. Newman, A., J., \& Patel, D. (2004). The marketing directions of two fashion retailers. European Journal of Marketing. Vol. 38, 770-789.

25. Palacios, L., L., López, R., P., \& Redondo, Y., P. Cognitive, affective and behavioural responses in mall experience: a qualitative approach. International Journal of Retail \& Distribution Management. Vol. 44. 2016.

26. Sherman, E., Mathur, A., \& Smith, R., B. Store Environment and Consumer Purchase Behavior: Mediating Role of Consumer Emotions. Psychology and 
Marketing. Vol. 14 (4), 1997. 361378.

27. Spangenberg, E., R., Crowley, A., E., \& Henderson, P., W.. Improving the store environment: do olfactory cues affect evaluations and behaviors? Journal of Marketing. Vol. 60 (2), 1996.p67-80.

28. Sweeney, J., C., \& Wyber, F. The role of cognitions and emotions in the music - approach - avoidance behavior relationship. Journal of Services Marketing. Vol. 16 (1), 2002. 51-69.

29. Wakefield, K., L., \& Baker, J. Excitement at the mall: determinants and effects on shopping response. Journal of Retailing. Vol. 74, 1998. 515- 539.

30. Zeithaml, V., A. Consumer perceptions of price, quality, and value: a meansend model and synthesis of evidence. Journal of Marketing. Vol. 52, 1988. 2-22. 